\title{
Active ageing in Europe: are changes in social capital associated with engagement, initiation and maintenance of activity in later life?
}

\author{
Pryanka Boerio $^{1 \star}$ (D), Emma Garavaglia ${ }^{2}$ (D) and Alessandra Gaia ${ }^{1}$ (D) \\ ${ }^{1}$ Department of Sociology and Social Research, University of Milan-Bicocca, Milan, Italy and ${ }^{2}$ WWELL \\ Research Centre, Department of Sociology, Università Cattolica del Sacro Cuore, Milan, Italy \\ ${ }^{*}$ Corresponding author. Email: pryanka.boerio@unimib.it
}

(Accepted 8 June 2021; first published online 29 July 2021)

\begin{abstract}
The demographic landscape of European countries is rapidly changing because of population ageing; in this context, societies are called to offer older people opportunities to age actively. Although 'active ageing' has been broadly explored, there is still room to further our knowledge on the individual conditions that may favour or hinder activity in later life. This study aims to contribute to the literature in this field by focusing on the role of social capital. Specifically, it explores, through logistic regression models, how social capital and changes in social capital are associated with engagement in, the initiation of and continued participation in various domains of activity: volunteering and charity work, active participation in political or community-related organisations, informal care-giving and paid work. The data analysed stem from the Survey of Health, Ageing and Retirement in Europe (SHARE). We focused on people aged 55+ participating in Waves 4-6. The key findings are: (a) having a larger social network is positively associated with participation in and the initiation of activities; (b) receiving social support (rarely) may stimulate reciprocity and thus care-giving; and (c) an increase in social network size is positively associated with initiation and maintenance of activities during later life.
\end{abstract}

Keywords: social capital; social network; active ageing; older people; Survey of Health Ageing and Retirement in Europe (SHARE); quantitative research

\section{Introduction}

Population ageing has affected the demographic landscape of European societies to the point where the traditional conception of the lifecourse, associating old age with a phase of decline and rest, is no longer realistic nor sustainable (Boudiny and Mortelmans, 2011). This shift has been accompanied and sustained by the emergence of the concept of 'active ageing'. The World Health Organization (2002:

\footnotetext{
(C) The Author(s), 2021. Published by Cambridge University Press. This is an Open Access article, distributed under the terms of the Creative Commons Attribution-NonCommercial-NoDerivatives licence (http://creativecommons.org/ licenses/by-nc-nd/4.0/), which permits non-commercial re-use, distribution, and reproduction in any medium, provided the original work is unaltered and is properly cited. The written permission of Cambridge University Press must be obtained for commercial re-use or in order to create a derivative work.
} 
12) defines active ageing as the 'process of optimizing opportunities for health, participation and security in order to enhance quality of life as people age', specifying that the term 'active' 'refers to continuing participation in social, economic, cultural, spiritual and civic affairs, not just the ability to be physically active or to participate in the labour force'. The concept of active ageing has rapidly and broadly spread in the scientific and political debate; additionally, the concept has guided the development of policy and interventions across Europe (Ney, 2005; Walker, 2006). Nevertheless, its definition is still debated, both in the scientific and political arena. In particular, there is a lack of agreement on the kinds of activities that should be considered when discussing active participation in later life. On the one hand, part of the literature adopts an exclusively economic framework and restricts the notion of activity in later life to paid work (Boudiny, 2013; Foster and Walker, 2013). However, focusing only on labour market participation overlooks a multiplicity of activities that produce social value, which is not monetised but still significant (Boudiny and Mortelmans, 2011; Lee et al., 2012). On the other hand, an overly broad definition of activity may prove ineffective when adopted in empirical research (Kim, 2020). A viable compromise involves considering all kinds of activities that produce a contribution to community life, regardless of whether such activities are paid or unpaid (Bass et al., 1993). This definition includes volunteering, care-giving, paid work and any other engagement in active roles that benefits not only the actor but also society.

Despite its popularity, the prospect of active ageing has raised some controversial issues. First, an important question concerns whether individuals can engage in various forms of activity at the same time (Lindley et al., 2014; Morrow-Howell et al., 2014). As Boudiny (2013: 1094) maintains, 'active ageing cannot be reduced to the sum of its indicators as various forms of activity are not necessarily complementary (e.g., possible tension between work and care responsibilities)'; thus, it is important to examine the combination of and interrelations between different activity domains to grasp fully the meaning of activity in later life (van der Horst et al., 2017).

Another relevant question concerns the conditions that may favour or hinder older people's activity. The literature (e.g. McNamara and Gonzales, 2011; Kim, 2020) shows that, above all, later-life activity patterns are influenced by human, cultural and social capital (SC); these are individual capitals, namely individual assets that provide access to other forms of resources (Bourdieu, 1986). For example, higher educational levels predict higher levels of activity, especially paid work and volunteering (Maestas, 2010; Forbes and Zampelli, 2014). Exploring the mechanisms through which various forms of capital affect active ageing contributes to understanding why some older people engage in some forms of activity while others do not; thus, it is particularly relevant to broaden the opportunities available and remove existing barriers (Raymond et al., 2014). This, in turn, can prevent the widening of the gap between older adults who can age actively and those who cannot. This gap, as stressed by critical gerontologists and sociologists (Moody, 1993; Estes and Mahakian, 2001), might favour the development of attitudes and practices stereotyping, in a negative way, the inactive/unproductive (dependent) older adult.

Our work follows this invitation and aims to explore whether and to what extent SC affects activity in old age. Through logistic regressions, the study analyses older 
people's participation in various domains of activity, namely volunteering and charity work, participation in political or community-related organisations, informal care-giving and paid work. The data analysed stem from the Survey of Health, Ageing and Retirement in Europe (SHARE).

The research advances the literature in this area by studying SC dynamically. To our knowledge, this is the first European study to investigate the association between changes in individual SC and participation in various domains of activity over time. Specifically, the study explores how SC and changes in SC are associated with engagement in, the initiation of and continued participation in paid work, volunteering, caring and-adhering to scholars' calls to consider a wide range of activities (Serrat et al., 2017; Kim, 2020) - also political participation.

The research highlights that SC is associated with engagement in and the initiation of activities in later life. Furthermore, changes in SC, in particular in social network (SN) size, are associated with the initiation and maintenance of these activities.

\section{Social capital and active ageing}

Different forms of individual capital (including SC) affect whether and to what extent older people engage in various forms of activity (Forbes and Zampelli, 2014; Gonzales and Nowell, 2017; Kim, 2020). The concept of capital refers to individual resources with tangible value that can be employed to obtain access to other forms of resources (Bourdieu, 1986).

The current paper explores active ageing in relation to one form of individual capital: SC. SC can be defined as the 'collection of resources owned by the members of an individual's personal social network, which may become available to the individual as a result of the history of these relationships' (van der Gaag, 2005: 20).

SC is a resource that actors can use to realise their interests, and similar to physical and human capital, it can facilitate productive activities (Coleman, 1990). This consideration also holds true for older people; indeed, both bonding SC (characterised by closed networks and particularised trust) and bridging SC (characterised by open networks across social cleavages and generalised trust) affect older adults' activity in later life (Musick and Wilson, 2007; McNamara and Gonzales, 2011). For example, regardless of their age, individuals with greater bridging SC have more chances to be recruited as volunteers (Putnam, 2000; Wilson, 2000; Musick and Wilson, 2007).

Conversely, the effect of bonding SC, such as family relationships, on participation in volunteering may go in two opposite directions. On the one hand, older volunteers tend to recruit other family members into volunteering (Morrow-Howell et al., 2008; Tang and Morrow-Howell, 2008), and consistently, married older adults are more likely to volunteer than non-married adults (Bowen et al., 2000; Butrica et al., 2009; McNamara and Gonzales, 2011). On the other hand, family responsibilities may limit the availability of resources for volunteering (Morrow-Howell et al., 2008).

Regarding care-giving, older adults with greater SC are more often engaged in caring for grandchildren, other family members and/or friends (Kim, 2020). It is not only the characteristics of one's SN (e.g. having a relative or friend who is 
chronically ill) that affects the probability of being involved in care-giving but also the degree of support received from the network's members, as this stimulates reciprocity (Wilson, 2000; Kim, 2020).

Concerning participation in paid work, the characteristics of older adults' SN affect their chances of remaining in employment. In particular, the stronger the SN ties and the higher the ties' employment prestige, the greater the potential for one's SC to favour employment in later life. Moreover, while younger workers evaluate their human capital as their main asset in their job searches, older workers consider their SC to be more important (Gayen et al., 2010).

Despite, overall, the literature from this field offering interesting insights into the relation between SC and various forms of activity in later life, some important gaps remain. First, with few exceptions (e.g. Gayen et al., 2010; Forbes and Zampelli, 2014; Kim, 2020), the literature is rather lacking studies that explore the relation between SC and older people's engagement in multiple activities at the same time.

Second, most studies overlook changes in engagement over time. Both of these gaps may exist due to the fact that most of the existing studies are cross-sectional (Forbes and Zampelli, 2014; Dávila, 2018) and do not allow us to understand multiple pathways of engagement. Since older people engage in various active roles at the same time (Morrow-Howell et al., 2014) and their domains and degrees of engagement may vary over time, longitudinally observing multiple activities allows for the adoption of a more comprehensive view of active ageing and its predictors (van der Horst et al., 2017; Strauss, 2021). A recent work by Kim (2020) constitutes an exception in relation to these gaps, as it analyses multiple activities using longitudinal data. The author explores whether human, cultural and social capital predict older adults' baseline participation and changes in engagement in various activities over time. The study uses two waves of panel data from the National Social Life, Health, and Aging Project, a representative, population-based sampling of older adults in the United States of America. The results offer interesting insights into the factors that promote or prevent older Americans' continued engagement in paid work, volunteering and caring. In particular, the author shows that older adults with greater SC are generally more engaged in the different activities (even though the relation between SC and activity is not apparent over the five-year period considered). Moreover, Kim (2020) highlights that married people are more likely to participate in care-giving and that the size of their networks is positively associated with the initiation of care-giving. Concerning participation in volunteering, the author shows that older adults with greater bridging SC are more likely to be recruited for volunteering and to continue to volunteer over time.

Third, even if some studies (Ajrouch et al., 2016; Strauss, 2021) have noted that changes in the SN structure - an important component of SC (Sabatini, 2009) may influence active ageing, none have tested this intuition empirically, studying changes in SC over time rather than analysing it at a single point in time.

Following the work of Kim (2020), this study aims to contribute to fill the gaps mentioned by analysing the relation between older adults' SC and engagement in various domains of activity at the same time and adopting a dynamic view of SC. To our knowledge, this is the first European study of this kind. In particular, this work explores how changes in individual SC are associated with the initiation of and continued participation in paid work, volunteering and care-giving and, 
adhering to Kim's (2020) call to consider a wider range of activities, it includes political participation as well, which to date has been largely overlooked (Serrat et al., 2017; Kim, 2020).

Specifically, the study addresses the following research questions (RQ):

(1) Is SC associated with baseline participation in activities (giving care, doing voluntary or charity work, participating in political or community-related organisations and doing paid work) in later life?

(2) Is SC associated with the initiation of activities in later life?

(3) Are changes in SC associated with the initiation of activities in later life?

(4) Are changes in SC associated with maintenance of the level of activity in the various domains under study?

\section{Data}

We use data from SHARE Waves 4-6 (Börsch-Supan, 2019a, 2019b, 2019c). SHARE is a biennial longitudinal study collecting data on older people's health, socio-economic status and SN (Börsch-Supan et al., 2013). The study has collected data since 2004 via computer-assisted personal interviewing on 140,000 individuals aged 50+, covering 28 European countries and Israel. For most countries, SHARE uses a multi-stage stratified sampling design (Bergmann et al., 2019).

Our analysis is conducted on Waves 4-6, given that questions on SNs are asked in Waves 4 and 6, and questions about activities and social support are asked in every wave. Data from Waves 4-6 were collected biennially between 2011 and 2015. We consider Wave 6 as the baseline (i.e. $t_{(0)}$, starting point for comparison) while Wave 5 represents $t_{(-1)}$ and Wave 4 represents $t_{(-2)}$. Following Strauss (2021) and van der Horst et al. (2017), we include in our analysis respondents aged 55 or older at baseline. We restrict our sample to individuals living in countries that took part in all three considered waves: Austria, Germany, France, Switzerland, Belgium, Sweden, Denmark, Spain, Italy, Czech Republic, Slovenia and Estonia. The resulting analysis sample is composed of 28,361 individuals (Table 1). However, models predicting the initiation of activities are based on a restricted sample (i.e. only respondents inactive at $t_{(-2)}$ and $\left.t_{(-1)}\right)$. Models predicting maintenance are based only on respondents who are active at $t_{(-2)}$.

\section{Methods}

To answer our research questions, we applied a set of logistic regression models.

\section{Dependent variables}

Dependent variables are a number of indicators of activity. For each indicator we consider (a) whether the respondent participates in the activity, (b) initiates the activity and (c) maintains the activity.

To measure participation in paid work, we create a binary variable with value 1 if the respondent works at least one hour in a typical week and 0 otherwise. To measure engagement in care-giving, we create a binary variable with value 1 in the case 
Table 1. Data description

\begin{tabular}{|c|c|}
\hline Variables & $\%$ or mean (SD) \\
\hline \multicolumn{2}{|l|}{ Controls: } \\
\hline Age & $69.6(0.12)$ \\
\hline \multicolumn{2}{|l|}{ Gender: } \\
\hline Female & 55.5 \\
\hline Male & 44.5 \\
\hline \multicolumn{2}{|l|}{ Level of education: } \\
\hline Primary & 48.5 \\
\hline Secondary & 30.7 \\
\hline Post-secondary & 20.8 \\
\hline \multicolumn{2}{|l|}{ Mental health (EURO-D, dichotomised): } \\
\hline Presence of depression & 28.6 \\
\hline No presence of depression & 71.4 \\
\hline \multicolumn{2}{|l|}{ Self-perceived health (SPH): } \\
\hline Poor & 11.3 \\
\hline Fair & 29.0 \\
\hline Good & 39.4 \\
\hline Very good & 14.6 \\
\hline Excellent & 5.8 \\
\hline \multicolumn{2}{|l|}{ Make ends meet: } \\
\hline With difficulty & 10.3 \\
\hline With some difficulty & 22.7 \\
\hline Fairly easily & 29.6 \\
\hline Easily & 37.3 \\
\hline \multicolumn{2}{|l|}{ Dependent variables: } \\
\hline \multicolumn{2}{|l|}{ Engagement in: } \\
\hline Care-giving & 41.9 \\
\hline Voluntary or charity work & 17.3 \\
\hline Political or community organisation & 6.5 \\
\hline Paid work & 26.1 \\
\hline \multicolumn{2}{|l|}{ Initiation of: } \\
\hline Care-giving & 25.3 \\
\hline Voluntary or charity work & 5.6 \\
\hline Political or community organisation & 3.0 \\
\hline Paid work & 2.1 \\
\hline
\end{tabular}

(Continued) 
Table 1. (Continued.)

\begin{tabular}{|c|c|c|c|}
\hline Variables & & $\%$ or mean $(\mathrm{SD})$ & \\
\hline \multicolumn{4}{|l|}{ Maintenance of: } \\
\hline Care-giving & & 40.1 & \\
\hline Voluntary or charity work & & 40.9 & \\
\hline Political or community organisation & & 31.5 & \\
\hline Paid work & & 55.7 & \\
\hline \multicolumn{4}{|l|}{ Explanatory variables: } \\
\hline Social network size & & $2.8(0.02)$ & \\
\hline \multicolumn{4}{|l|}{ Partner: } \\
\hline Single & & 34.4 & \\
\hline Without limitations & & 50.7 & \\
\hline With limitations & & 5.1 & \\
\hline Outside the household & & 2.7 & \\
\hline Inside household - no health & & 6.6 & \\
\hline \multicolumn{4}{|l|}{ Social support received: } \\
\hline Never & & 75.6 & \\
\hline Less than monthly & & 6.0 & \\
\hline Monthly & & 3.7 & \\
\hline Weekly & & 6.5 & \\
\hline Daily & & 8.2 & \\
\hline Changes in social capital: & Decrease & No change & Increase \\
\hline Social network size & 31.2 & 28.6 & 40.2 \\
\hline Partner with limitations & 3.7 & 79.5 & 3.4 \\
\hline Social support received & 11.3 & 69.5 & 19.1 \\
\hline
\end{tabular}

Notes: Data are weighted with Survey of Health, Ageing and Retirement in Europe (SHARE) Wave 6 cross-sectional calibration weights. SD: standard deviation.

Source: Survey of Health, Ageing and Retirement in Europe.

of care-giving in the last 12 months and 0 otherwise. Care-giving includes both help within the household and help outside the household to family, friends and/or neighbours. Types of care considered are personal care (e.g. dressing, eating and getting into or out of bed), practical household help (e.g. home repairs, gardening and shopping), help with paperwork (e.g. filling out forms and settling financial or legal matters) and looking after grandchildren. We define 'non-care-givers' as all respondents declaring that they do not provide support on any variable (i.e. care within the household, outside the household or to grandchildren) and having missing values in all other variables. To measure participation in volunteering and political participation, we create two binary variables with value 1 in the case of participation in these activities in the last year and 0 otherwise. 
Initiation is measured as participation in an activity at $t_{(0)}$ for those inactive at $t_{(-1)}$ and $t_{(-2)}$ (in that specific activity). The resulting four variables (namely initiation of paid work, care-giving, volunteering and political participation) take value 1 if the respondent initiated the activity at $t_{(0)}$ (and was inactive at $t_{(-1)}$ and $t_{(-2)}$ ) and 0 if he or she never engaged in the activity. All other cases are set to missing.

Maintenance is measured through frequency of activities. For measuring maintenance, we create a variable taking value 1 if the respondent maintained constant hours or increased the number of hours worked (in a typical week) between $t_{(0)}$ and $t_{(-2)}$ (i.e. remained in the same quartile of numbers of hours worked or moved to a higher quartile) and 0 otherwise (i.e. moved to a lower quartile of numbers of hours worked/ceased the activity).

To measure maintenance in care-giving, volunteering and political participation we create binary variables - taking value 1 if the respondent maintains or increases his or her frequency of activity (which takes values: about daily, about once a week, about once a month, less often, never) and 0 if he or she decreases the frequency or stops performing the activity. Hence, we are able to distinguish between older people maintaining the same degree of involvement in a specific activity or increasing it and those decreasing their degree of involvement or stopping the activity completely. It should be noted that while for care-giving outside the household and for grandchildren, data on the frequency are available, for care-giving inside the household, only data on whether the respondent provides care are available (i.e. no information about frequency is collected). Given the pervasiveness of care-giving inside the household, we assumed that this activity requires the care-giver's involvement every day.

\section{Explanatory variables}

The explanatory variables are SC and changes in SC. Drawing on Kim (2020), SC is operationalised by network size, social support received and presence of a partner with/without limitations in activities of daily living (ADL). We operationalise network size as the number of contacts in the respondents' SNs (0-7). These data are collected at Waves 4 and 6 using a SN name generator, where respondents are asked to list up to six people with whom they have discussed important matters in the last year and one additional person who is 'important for any reason'.

Social support received includes support received from outside the household (personal care, practical household help and help with paperwork) and from inside the household. Frequency of support received inside the household takes values: about daily, about once a week, about once a month, less often or never. No information is available on the frequency of care received within the household; thus, similar to care-giving, we assume that support received within the household is very pervasive and requires involvement every day. Additionally, we consider as non-receiving support respondents declaring not to receive support in one of the two social support variables (i.e. support from inside/outside the household) and having a missing value in the other.

The presence of a partner with/without limitations in ADL is operationalised through the following categories: no partner, partner inside the household without limitations, partner inside the household with one (or more) limitations, partner outside the household, partner inside the household and no ADL data available. 
This variable is created by merging respondents' data with data from partners' interviews when available, i.e. respondents' partner is eligible for interview (co-habiting), participated in the survey and answered the item.

Changes in SN size are measured as the difference between SN sizes at $t_{(-2)}$ and $t_{(0)}$; the resulting variable ranges between -7 and +7 . Changes in social support received are measured with a variable taking values: 1 (indicating an increase in frequency of care received), 0 (no change) and -1 (a decrease). Changes in the presence of a co-habiting partner with/without ADL are measured with the following categories: no changes; loss of a co-habiting partner with ADL (i.e. having a partner with $\mathrm{ADL}$ at $t_{(-2)}$ and any other (valid) status at $\left.t_{(0)}\right)$; 'acquisition' of a co-habiting partner with ADL, i.e. having a partner with ADL at $t_{(0)}$ and any other (valid) status at $t_{(-2)}$; and no information about the co-habiting partner's ADL at $t_{(-2)}$ and/or at $t_{(0)}$.

\section{Control variables}

Demographic, socio-economic and health variables are included as controls. Specifically, the demographic variables considered are age and gender. Age is included as a continuous variable. Gender is included as a binary variable taking values 1 if the respondent is female and 0 if the respondent is male.

As indicator of social status, we use education, measured by the International Standard Classification of Education (ISCED 1997). We recode it into three categories: primary education, secondary education, and post-secondary education.

Economic situation is captured through a subjective income measure based on a question asking with which level of difficulty the household is able to make ends meet: great difficulty, some difficulty, fairly easily, and easily.

Health is measured by self-perceived health (SPH) and EURO-D. SPH is a selfreported measure of personal health varying between 1 (excellent) and 5 (poor). EURO-D is a measure of depression derived from 12 survey items. The index varies from 0 (no symptoms of depression) to 12 (all symptoms/very depressed). Following the approach proposed by Dewey and Prince (2005) and adopted by, for example, Croezen et al. (2015) and Bashkin et al. (2018), we recode the index as a binary variable using a cut-off score of 4 or greater to represent the presence of depression.

Finally, we control for the respondents' countries of residence.

\section{Modelling strategy}

To investigate the association between SC and engagement in activities (RQ1), we apply logistic regression models regressing engagement in activities on SC at $t_{(0)}$. Separate models are estimated for each activity.

To analyse whether SC predicts the initiation of activities (RQ2), we perform logistic regression models, regressing the initiation of (each) activity on SC at $t_{(0)}$. Given the low share of respondents initiating activities $(3.1 \%$ for political participation and 2.2\% for paid work), we adopt Penalized Maximum Likelihood estimation (PMLE), a method proposed by Firth (1993) for modelling rare events.

To analyse whether changes in SC $(\triangle \mathrm{SC})$ predict the initiation of activities (RQ3), we perform logistic regression models (with PMLE), regressing initiation 
in (each) activity on $\triangle \mathrm{SC}$. To investigate the effect of $\triangle \mathrm{SC}$ on the maintenance of frequency of engagement (RQ4), we perform logistic regression models, one for each activity.

In each model, we control for demographic, socio-economic and health variables, and for participation in the other activities at baseline. In models adopted to answer to RQ3 and RQ4, we also control for scores of SC at $t_{(-2)}$. To perform the analyses, we used the software Stata, version 15. Descriptive statistics are weighted with SHARE Wave 6 cross-sectional calibration weights.

\section{Results}

Table 2 shows the association between SC and participation in activities (RQ1). SN size is positively associated with care-giving (Model 1), volunteering (Model 2), political participation (Model 3) and paid work (Model 4).

Regarding partner presence, compared to respondents who are single, those co-habiting with a partner with limitations in ADL are almost three times more likely to provide care, while those co-habiting with a partner without limitations are less likely to provide care. Thus, having a co-habiting partner does not seem to encourage care-giving through SC but instead through the presence of a dependent adult in the household. However, SC might be the driver of care-giving for respondents with a partner but not co-habiting; these respondents have a higher likelihood of giving care than respondents who are single (Model 1). With respect to paid work, older people with a co-habiting partner are less likely to work (regardless of the partner's health), whereas those with a partner outside the household are more likely to work than respondents who are single (Model 4). No effect is detected for volunteering (Model 2) or political participation (Model 3).

With respect to care-giving, in comparison to respondents not receiving support, older people who do receive support are more likely to give care; this finding seems to signal that a reciprocity effect is at play. However, the stronger the effect is, the less frequently care is received. This result is not surprising as respondents receiving care very frequently (e.g. daily) may be less able to provide care for others (Model 1). Additionally, older people receiving support rarely (e.g. less than once a month) are more likely to do voluntary and paid work (Models 2 and 4) than those not receiving any support; conversely, respondents receiving care with high frequency (i.e. daily) are less likely to volunteer and work than respondents not receiving support. These findings are consistent with the evidence obtained on care-giving: receiving frequent care might signal a level of fragility that prevents volunteering and working, while receiving care monthly or less than monthly could stimulate generativity (not through care-giving addressed to loved ones but through a service offered to the community). No association is found, at the standard statistical level, between support received and political participation (Model 3).

Last, regarding involvement in multiple activities, a complementarity effect (rather than a substitution effect) emerges for care-giving, volunteering and political participation: older people involved in one of these activities are more likely to also be involved in other activities. Conversely, paid work is positively associated only with political participation (odds ratio $(\mathrm{OR})=1.406$ ), and it is negatively associated with voluntary/charity work $(\mathrm{OR}=0.897)$. This evidence seems to signal a 
Table 2. Logistic regression models predicting engagement in activity (RQ1)

\begin{tabular}{|c|c|c|c|c|}
\hline Variables & $\begin{array}{l}\text { Model 1: } \\
\text { Care-giving }\end{array}$ & $\begin{array}{l}\text { Model 2: } \\
\text { Volunteering }\end{array}$ & $\begin{array}{c}\text { Model 3: } \\
\text { Political } \\
\text { participation }\end{array}$ & $\begin{array}{c}\text { Model 4: } \\
\text { Paid } \\
\text { work }\end{array}$ \\
\hline & \multicolumn{4}{|c|}{ Odds ratios } \\
\hline \multicolumn{5}{|l|}{ Social capital: } \\
\hline Social network size & $1.175^{\star \star \star}$ & $1.084^{\star \star \star}$ & $1.131^{\star \star \star}$ & $1.068^{\star \star \star}$ \\
\hline \multicolumn{5}{|l|}{ Partner (Ref. Single) } \\
\hline Co-habiting, no limitation in ADL & $0.897^{\star \star}$ & 0.936 & 1.007 & $0.745^{\star \star \star}$ \\
\hline Co-habiting, limitation in ADL & $2.838^{\star \star \star}$ & 0.958 & 0.804 & $0.824^{\star}$ \\
\hline Not co-habiting & $1.271^{\star \star}$ & 0.890 & 1.179 & $1.250^{\star}$ \\
\hline Co-habiting, no ADL information & $1.720^{\star \star \star}$ & 0.900 & 0.974 & 0.992 \\
\hline \multicolumn{5}{|l|}{$\begin{array}{l}\text { Social support received (Ref. No } \\
\text { support) }\end{array}$} \\
\hline Less than monthly & $2.065^{\star \star \star}$ & $1.229^{\star \star}$ & 1.054 & $1.236^{\star \star}$ \\
\hline Monthly & $1.845^{\star \star \star}$ & $1.306^{\star \star}$ & 1.031 & 0.992 \\
\hline Weekly & $1.199^{\star \star}$ & 0.947 & 1.227 & $0.611^{\star \star \star}$ \\
\hline Daily & $1.128^{\star}$ & $0.727^{\star \star}$ & 1.067 & $0.554^{\star \star \star}$ \\
\hline \multicolumn{5}{|l|}{ Activity: } \\
\hline Care-giving & na & $1.642^{\star \star \star}$ & $1.203^{\star \star}$ & 1.058 \\
\hline Volunteering & $1.649^{\star \star \star}$ & na & $3.581^{\star \star \star}$ & 0.932 \\
\hline Political participation & $1.200^{\star \star}$ & $3.584^{\star \star \star}$ & na & $1.363^{\star \star \star}$ \\
\hline Paid work & 1.020 & $0.897^{\star}$ & $1.406^{\star \star \star}$ & na \\
\hline Constant & $0.220^{\star \star \star}$ & $0.038^{\star \star \star}$ & $0.013^{\star \star \star}$ & $0.006^{\star \star \star}$ \\
\hline $\mathrm{N}$ & 26,016 & 26,016 & 26,016 & 26,016 \\
\hline
\end{tabular}

Notes: All models include control variables: age (centred on mean), age-squared, gender, health, country, level of education and economic situation. Ref.: reference category. ADL: activities of daily living. na: not applicable. Source: Survey of Health, Ageing and Retirement in Europe.

Significance levels: ${ }^{*} p<0.05,{ }^{\star \star} p<0.01,{ }^{\star \star \star} p<0.001$.

substitution effect between volunteering and working (which might be more pervasive and demanding than the other activities).

Table 3 shows the association between SC and the initiation of activities (RQ2). SN size is positively associated with the initiation of care-giving (Model 1), voluntary work (Model 2), political activities (Model 3) and paid work (Model 4). Compared to single respondents, those with a partner are more likely to start care-giving. In particular, those co-habiting with a partner with limitations are about four times more likely to start care-giving than respondents without a partner (Model 1). Conversely, older people co-habiting with a partner with limitations in ADL are less likely to initiate political activities than respondents who are single (Model 3). No association at the standard statistical level is found regarding partner presence/health condition and the initiation of voluntary and paid work (Models 2 and 4). 
Table 3. Logistic regression models predicting initiation of activity (RQ2)

\begin{tabular}{|c|c|c|c|c|}
\hline Variables & $\begin{array}{l}\text { Model 1: } \\
\text { Care-giving }\end{array}$ & $\begin{array}{l}\text { Model 2: } \\
\text { Volunteering }\end{array}$ & $\begin{array}{l}\text { Model 3: } \\
\text { Political } \\
\text { participation }\end{array}$ & $\begin{array}{l}\text { Model 4: } \\
\text { Paid } \\
\text { work }\end{array}$ \\
\hline & \multicolumn{4}{|c|}{ Odds ratios } \\
\hline \multicolumn{5}{|l|}{ Social capital: } \\
\hline Social network size & $1.174^{\star \star \star}$ & $1.095^{\star \star \star}$ & $1.116^{\star \star \star}$ & $1.078^{\star}$ \\
\hline \multicolumn{5}{|l|}{ Partner (Ref. Single) } \\
\hline Co-habiting, no limitation in ADL & $1.474^{\star \star \star}$ & 0.922 & 0.830 & 0.890 \\
\hline Co-habiting, limitation in $A D L$ & $3.785^{\star \star \star}$ & 0.953 & $0.675^{\star}$ & 0.999 \\
\hline Not co-habiting & $1.638^{\star \star}$ & 1.017 & 0.949 & 1.137 \\
\hline Co-habiting, no ADL information & $1.552^{\star \star \star}$ & 0.830 & 0.774 & 1.011 \\
\hline \multicolumn{5}{|l|}{$\begin{array}{l}\text { Social support received (Ref. No } \\
\text { support) }\end{array}$} \\
\hline Less than monthly & $2.079^{\star \star \star}$ & 1.217 & 0.910 & $1.750^{\star \star}$ \\
\hline Monthly & $1.954^{\star \star \star}$ & 1.134 & 1.133 & $1.551^{\star}$ \\
\hline Weekly & $1.351^{\star \star}$ & 0.920 & 1.262 & 0.825 \\
\hline Daily & $1.305^{\star *}$ & $0.683^{*}$ & 1.066 & 0.693 \\
\hline \multicolumn{5}{|l|}{ Activity: } \\
\hline Care-giving & na & $1.571^{\star \star \star}$ & $1.187^{\star}$ & 1.164 \\
\hline Volunteering & $1.659^{\star \star \star}$ & na & $3.443^{\star \star \star}$ & 0.929 \\
\hline Political participation & $1.276^{\star \star}$ & $3.159^{\star \star \star}$ & na & $1.789^{\star \star}$ \\
\hline Paid work & 1.077 & 1.105 & $1.308^{\star}$ & na \\
\hline Constant & $0.087^{\star \star \star}$ & $0.015^{\star \star \star}$ & $0.005^{\star}$ & $0.003^{\star \star \star *}$ \\
\hline N & 11,114 & 19,227 & 23,157 & 16,137 \\
\hline
\end{tabular}

Notes: All models include control variables: age (centred on mean), age-squared, gender, health, country, level of education and economic situation. Ref.: reference category. ADL: activities of daily living. na: not applicable. Source: Survey of Health, Ageing and Retirement in Europe. Significance levels: ${ }^{\star} p<0.05,{ }^{\star \star} p<0.01,{ }^{\star \star \star} p<0.001$.

In comparison to respondents not receiving support, those who do receive support are more likely to initiate caring; the effect is stronger the lower the level of care received. We also detect a positive effect for starting paid work, but only for respondents receiving support rarely (versus no support received). Conversely, compared to respondents not receiving support, those receiving support daily/inside the household are less likely to start voluntary work, while no effect is found for those receiving support less frequently.

Again, a complementarity between care-giving, volunteering and political participation is found: individuals involved in one of these activities are more likely to start another activity. Complementarity is also present between political activities and paid work.

Table 4 shows effects of $\Delta \mathrm{SC}$ on the initiation of a new activity (RQ3). An increase in SN size is positively associated with the start of a care-giving activity 
Table 4. Logistic regression models predicting initiation of activity (RQ3)

\begin{tabular}{|c|c|c|c|c|}
\hline Variables & $\begin{array}{l}\text { Model 1: } \\
\text { Care-giving }\end{array}$ & $\begin{array}{c}\text { Model 2: } \\
\text { Volunteering }\end{array}$ & $\begin{array}{l}\text { Model 3: Political } \\
\text { participation }\end{array}$ & $\begin{array}{l}\text { Model 4: } \\
\text { Paid } \\
\text { work }\end{array}$ \\
\hline & \multicolumn{4}{|c|}{ Odds ratios } \\
\hline \multicolumn{5}{|l|}{ Social capital: } \\
\hline Social nework size change & $1.177^{\star \star \star}$ & $1.097^{\star \star \star}$ & $1.118^{\star \star \star}$ & $1.092^{\star}$ \\
\hline \multicolumn{5}{|l|}{$\begin{array}{l}\text { Partner (Ref. No change in } \\
\text { partnership status) }\end{array}$} \\
\hline $\begin{array}{l}\text { Lost a partner with } \\
\text { limitations in } A D L\end{array}$ & $0.470^{\star \star}$ & 1.103 & 0.967 & 0.614 \\
\hline $\begin{array}{l}\text { New partner with } \\
\text { limitations in } A D L\end{array}$ & $2.645^{\star \star \star}$ & 0.981 & 0.733 & 1.076 \\
\hline No partner information & 1.075 & 1.094 & 1.005 & 1.321 \\
\hline \multicolumn{5}{|l|}{$\begin{array}{l}\text { Social support received } \\
\text { (Ref. No change in frequency } \\
\text { of support received) }\end{array}$} \\
\hline Decrease & $1.351^{\star}$ & 1.374 & 1.298 & 1.044 \\
\hline Increase & $1.739^{\star \star \star}$ & 1.105 & 1.050 & 1.152 \\
\hline \multicolumn{5}{|l|}{ Activity: } \\
\hline Care-giving & na & $1.596^{\star \star \star}$ & 1.067 & 1.273 \\
\hline Volunteering & $1.771^{\star \star \star}$ & na & $3.660^{\star \star \star}$ & 0.999 \\
\hline Political participation & 1.193 & $3.205^{\star \star \star}$ & na & $1.612^{*}$ \\
\hline Paid work & 1.146 & 1.068 & 1.236 & na \\
\hline Constant & $0.083^{\star \star \star}$ & $0.016^{\star \star \star}$ & $0.005^{\star \star \star}$ & $0.003^{\star \star \star}$ \\
\hline $\mathrm{N}$ & 8,287 & 16,240 & 19,479 & 14,014 \\
\hline
\end{tabular}

Notes: All models include control variables: age (centred on mean), age-squared, gender, health, country, level of education, economic situation and social capital at Wave 4. Ref.: reference category. ADL: activities of daily living. na: not applicable.

Source: Survey of Health, Ageing and Retirement in Europe.

Significance levels: ${ }^{\star} p<0.05,{ }^{\star \star} p<0.01,{ }^{\star \star \star} p<0.001$.

(Model 1), voluntary work (Model 2), political activities (Model 3) and paid work (Model 4).

Compared to older people showing no changes in partnership status, those losing a partner with limitations are less likely to start a care-giving activity, while those with a 'new' partner with limitations in ADL (e.g. having a co-habiting partner whose health worsens) are about two and half times more likely to provide care. Finally, changes (increase/decrease) in support received increase the odds of initiating care for others.

Table 5 shows the effect of $\Delta \mathrm{SC}$ on maintenance of activity (RQ4). An increase in $\mathrm{SN}$ size is positively associated with maintaining/increasing the frequency of caregiving (Model 1), volunteering (Model 2) and political participation (Model 3). 
Table 5. Logistic regression models predicting maintenance of activity (RQ4)

\begin{tabular}{|c|c|c|c|c|}
\hline Variables & $\begin{array}{l}\text { Model 1: } \\
\text { Care-giving }\end{array}$ & $\begin{array}{l}\text { Model 2: } \\
\text { Volunteering }\end{array}$ & $\begin{array}{l}\text { Model 3: } \\
\text { Political } \\
\text { participation }\end{array}$ & $\begin{array}{l}\text { Model 4: } \\
\text { Paid } \\
\text { work }\end{array}$ \\
\hline & \multicolumn{4}{|c|}{ Odds ratios } \\
\hline \multicolumn{5}{|l|}{ Social capital: } \\
\hline Social network size change & $1.095^{\star \star \star}$ & $1.067^{\star \star}$ & $1.095^{\star}$ & 1.000 \\
\hline \multicolumn{5}{|l|}{$\begin{array}{l}\text { Partner (Ref. No change in } \\
\text { partnership status) }\end{array}$} \\
\hline $\begin{array}{l}\text { Lost a partner with limitations } \\
\text { in } A D L\end{array}$ & $0.167^{\star \star \star}$ & 1.134 & 1.109 & 0.690 \\
\hline $\begin{array}{l}\text { New partner with limitations in } \\
A D L\end{array}$ & $3.215^{\star \star \star}$ & 0.980 & 0.784 & 0.947 \\
\hline No partner information & 1.378 & 1.148 & 0.634 & 1.279 \\
\hline \multicolumn{5}{|l|}{$\begin{array}{l}\text { Social support received (Ref. No } \\
\text { change in frequency of support } \\
\text { received) }\end{array}$} \\
\hline Decrease & $0.631^{\star \star \star}$ & 1.353 & 1.208 & 1.160 \\
\hline Increase & 1.044 & 1.061 & 0.757 & 0.969 \\
\hline \multicolumn{5}{|l|}{ Activity: } \\
\hline Care-giving & na & $1.409^{\star \star \star}$ & $1.470^{\star \star}$ & 1.044 \\
\hline Volunteering & $1.366^{\star \star \star}$ & na & $1.865^{\star \star \star}$ & 0.939 \\
\hline Political participation & 0.898 & $1.797^{\star \star \star}$ & na & 1.024 \\
\hline Paid work & 1.073 & $0.769^{\star \star}$ & 1.204 & na \\
\hline Constant & $0.331^{\star \star \star}$ & $0.191^{\star \star \star}$ & $0.203^{* *}$ & $0.158^{\star \star *}$ \\
\hline $\mathrm{N}$ & 10,225 & 3,906 & 1,380 & 5,749 \\
\hline
\end{tabular}

Notes: All models include control variables: age (centred on mean), age-squared, gender, health, country, level of education, economic situation and social capital at Wave 4. Ref.: reference category. ADL: activities of daily living. na: not applicable.

Source: Survey of Health, Ageing and Retirement in Europe.

Significance levels: ${ }^{*} p<0.05,{ }^{\star *} p<0.01,{ }^{\star \star *} p<0.001$.

Older people losing a partner with limitations are less likely to maintain the same level of engagement in care-giving than respondents experiencing no changes in partner health. Respondents in the opposite situation (i.e. having a co-habiting partner with a limitation at $t_{(0)}$ and not having a partner with limitation at $\left.t_{(-2)}\right)$ are about three times more likely to maintain/increase levels of engagement in care-giving. Furthermore, a decrease in support received reduces the odds of starting to care for others compared to not experiencing any changes in the amount of support received.

Regarding involvement in multiple activities, we find mixed results. Regarding the association between participation in each activity and the level of maintenance, we observe complementarity between care-giving and volunteering; additionally, we observe complementarity between volunteering and political participation. 
Moreover, maintenance of political participation is also positively associated with care-giving, while we find no effect of political participation on maintenance of care-giving. A substitution effect emerges between paid work and volunteering. Last, maintenance of a certain degree of engagement in paid work seems not to be related to any of the variables under study.

\section{Discussion and conclusion}

This paper shows that many older people in Europe are engaged in a variety of activities that contribute to community life beyond paid work: 42 per cent of respondents give care to other people, 26 per cent do paid work, 17 per cent do voluntary work and 6 per cent participate in political activities.

Independent of participation level, we found evidence for a relationship between three key components of SC - the size of one's SN, having a partner and receiving support - and participation in, as well as the initiation and maintenance of, some of the activities under study.

In general, the analysis shows that having a larger $\mathrm{SN}$ is positively associated with participation in care-giving, volunteering, political organisations and paid work in later life as well as with starting to be active in these domains for those previously inactive. It is, however, beyond the scope of this analysis to assess whether this association is causal; reverse causality may also be at play given that participation in activities can increase older people's SN size.

While SN size is positively associated with participation in all domains, the relation between having a partner and being active in the various domains is not always significant at standard statistical levels. In particular, older people co-habiting with a partner have more chances to initiate care-giving (especially if the partner has health problems, as one can easily expect) and fewer chances to engage in paid work (if the partner is inside the household). Contrary to previous research (Butrica et al., 2009; McNamara and Gonzales, 2011), the association between having a partner (regardless of his or her health) and volunteering is not significant. The same is true for participation in political organisations, except for older people with a partner with health limitations who are less likely to start being engaged in this form of active citizenship. These results seem to confirm that, also in later life, participation in care-giving and paid work needs to be explored as part of the household needs and labour allocation. Last, receiving the support needed seems to favour activity in later life and the initiation of new activities, and this might relate, as other studies show (Kim, 2020), to the fact that benefiting from help stimulates reciprocity. Of course, when older people receive support very often, the relation between support received and activity is negative, as needing help very often might indicate a disadvantaged condition (concerning health or material resources, among others) that prevents participation (as also speculated by Reinhardt et al., 2006).

Analysing whether changes in SC are associated with active ageing, results clearly show that an increase in the number of social connections predicts a higher probability of engaging in all forms of activity under examination as well as maintaining or increasing the degree of engagement (in terms of frequency of participation), in most activities. 
Another relevant aspect emerging from the study is the complementarity between some of the areas of activation. In fact, controlling for co-habitation with a partner with health limitations, we found evidence for a complementary relation between care-giving, volunteering and participation in political organisations; conversely, the relation between paid work and the other activities is less consistent. This might suggest that having a job does not always allow for the combination of paid and unpaid work. In general, these results seem consistent with the literature (see Caro et al., 2005) suggesting that, given certain prerequisites, a motivation to be active in later life - beyond engagement in paid work - seems to exist regardless of the specific domain of activity.

We feel that both important policy implications - as well as suggestions on further areas of research - emerge from this work. First, the study shows that older people living with a partner who has health limitations are less frequently involved in paid work and less likely to initiate participation in politics than single older individuals. Thus, our results seem to suggest the need to make emotional, practical and financial support available and easily accessible for older people co-habiting with a partner who has health limitations. In general, we agree with the claim also highlighted in other recent contributions (see van der Horst et al., 2017) that the combination of factors influencing older people's involvement in various domains of activities is very complex and needs to be investigated further, also through qualitative research.

Second, another important policy implication emerges from the finding that paid work does not seem to occur simultaneously with activation in other domains of activity. We do not assess whether this lack of co-activation is the result of individual preferences or whether it is associated with a lack of resources (e.g. time constraints, lack of opportunities). Nevertheless, since it has been demonstrated that participating actively in the community, e.g. through volunteering, may facilitate a smoother transition into retirement (Tang, 2016), the promotion of a combination of paid and unpaid work in old age needs to be brought to the attention of relevant stakeholders, such as employers and human resource managers. In fact, although a certain number of good practices in the field of age management can be identified across Europe (Garavaglia et al., 2020) and include managerial policies and practices aimed at promoting older workers' successful transition into retirement, there is still much room for the engagement of managers and employers in this field (Oude Mulders et al., 2020).

Overall, the study results stress the importance of approaching the issue of active ageing - in particular, of the active participation of older people in various domains of social life - through a critical lens. In fact, our results show that people have differentiated opportunities to age actively. These opportunities are affected by individual conditions, and SC plays a relevant role in this sense. Thus, policy makers and all relevant stakeholders who engage in active ageing promotion need to dedicate specific resources to create the conditions necessary for activity in later life, for all. In particular, we stress the importance of providing older people, especially those living alone or in isolation, with opportunities to connect with other people and build meaningful relations. Otherwise, active ageing promotion policies and initiatives risk producing unintended marginalisation effects by broadening the gap between older adults who can age actively and those who cannot. 
This study has two main limits. First, we are not able to assess whether the identified associations are causal in nature, and which is the direction of the causal link, if present. Second, while we do consider the effect of SC on activities and the complementarity/substitution effect of each activity, we do not study the effect of the interaction between SC and each activity on the other activities under study. Further research may also investigate aspects extending beyond the focus of this paper, such as gender differences and differences between age groups (within the old-age population), of the association between SC and active ageing.

Data. This paper uses data from SHARE Waves 4, 5, and 6 (10.6103/SHARE.w4.700, 10.6103/ SHARE.w5.700, 10.6103/SHARE.w6.700), see Börsch-Supan et al. (2013) for methodological details. (1) The SHARE data collection has been funded by the European Commission, DG RTD through FP5 (QLK6-CT-2001-00360), FP6 (SHARE-I3: RII-CT-2006-062193, COMPARE: CIT5-CT-2005-028857, SHARELIFE: CIT4-CT-2006-028812), FP7 (SHARE-PREP: GA N²11909, SHARE-LEAP: GA N ${ }^{\circ}$ 227822, SHARE M4: GA N²61982, DASISH: GA N²83646) and Horizon 2020 (SHARE-DEV3: GA N676536, SHARE-COHESION: GA N870628, SERISS: GA N654221, SSHOC: GA N823782) and by DG Employment, Social Affairs \& Inclusion through VS 2015/0195, VS 2016/0135, VS 2018/0285, VS 2019/0332, and VS 2020/0313. Additional funding from the German Ministry of Education and Research, the Max Planck Society for the Advancement of Science, the U.S. National Institute on Aging (U01_AG09740-13S2, P01_AG005842, P01_AG08291, P30_AG12815, R21_AG025169, Y1-AG-4553-01, IAG_BSR06-11, OGHA_04-064, HHSN271201300071C, RAG052527A) and from various national funding sources is gratefully acknowledged (see www.share-project.org).

Acknowledgements. We thank our colleague Emanuela Sala for useful insights and comments on an earlier version of this paper. We also thank Andrea Geraci for the useful suggestions on how to improve our analytical strategy. The responsibility for the content of the article lies entirely with the authors.

Author contributions. All authors contributed equally to the conception of the study, design of the analysis plan and interpretation of the data. PB performed the data analysis, under the supervision of AG. EG drafted the introduction, the section on the literature review and the conclusion, PB and AG drafted the section on methods and results. All authors revised, read and approved the whole manuscript.

Financial support. This work was supported by Fondazione Cariplo (grant 'Bando 2017, ricerca scientifica: Ricerca sociale sull'invecchiamento: persone, luoghi e relazioni. Project number 2017-0946; project name 'Aging in a Networked Society. Older People, Social Networks and Well-Being').

Conflict of interest. The authors declare no conflicts of interest.

Ethical standards. Ethical approval was not required as the empirical research is based uniquely on secondary data analysis.

\section{References}

Ajrouch KJ, Antonucci TC and Webster NJ (2016) Volunteerism: social network dynamics and education. Journals of Gerontology: Psychological Sciences and Social Sciences 71B, 309-319.

Bashkin O, Horne R and Bridevaux IP (2018) Influence of health status on the association between diabetes and depression among adults in Europe: findings from the SHARE international survey. Diabetes Spectrum 31, 75-82.

Bass SA, Caro FG and Chen YP (eds) (1993) Achieving a Productive Aging Society. Westport, CT: Auburn House.

Bergmann M, Kneip T, De Luca G and Scherpenzeel A (2019) Survey participation in the Survey of Health, Ageing and Retirement in Europe (SHARE), Wave 1-7. Based on Release 7.0.0. SHARE-ERIC, Munich, SHARE Working Paper Series 41-2019. Available at http://www.share-project. org/uploads/tx_sharepublications/WP_Series_41_2019_Bergmann_et_al.pdf. 
Börsch-Supan A (2019a) Survey of Health, Ageing and Retirement in Europe (SHARE) Wave 4. Release version 7.0.0. SHARE-ERIC. Data set. DOI:10.6103/SHARE.w4.700.

Börsch-Supan A (2019b) Survey of Health, Ageing and Retirement in Europe (SHARE) Wave 5. Release version 7.0.0. SHARE-ERIC. Data set. DOI:10.6103/SHARE.w5.700.

Börsch-Supan A (2019c) Survey of Health, Ageing and Retirement in Europe (SHARE) Wave 6. Release version 7.0.0. SHARE-ERIC. Data set. DOI:10.6103/SHARE.w6.700.

Börsch-Supan A, Brandt M, Hunkler C, Kneip T, Korbmacher J, Malter F, Schaan B, Stuck S and Zuber S (2013) Data resource profile: the Survey of Health, Ageing and Retirement in Europe (SHARE). International Journal of Epidemiology 42, 992-1001.

Boudiny K (2013) 'Active ageing': from empty rhetoric to effective policy tool. Ageing \& Society 33, 1077-1098.

Boudiny K and Mortelmans D (2011) A critical perspective: towards a broader understanding of 'active ageing'. E-Journal of Applied Psychology 7, 8-14.

Bourdieu P (1986) The forms of capital. In Richardson JG (ed.), Handbook of Theory and Research for the Sociology of Education. New York, NY: Greenwood, pp. 241-258.

Bowen DJ, Andersen MR and Urban N (2000) Volunteerism in a community-based sample of women aged 50 to 80 years. Journal of Applied Social Psychology 30, 1829-1842.

Butrica BA, Johnson RW and Zedlewski SR (2009) Volunteer dynamics of older Americans. Journals of Gerontology: Psychological Sciences and Social Sciences 64B, 644-655.

Caro FG, Bruner-Canhoto L, Burr J and Mutchler J (2005) Motivation for active aging: results of a pilot study. Gerontology Institute, University of Massachusetts, Boston, MA, Gerontology Institute Publications Paper 14. Available at https://scholarworks.umb.edu/cgi/viewcontent.cgi?referer=https://www.google.com/ \&httpsredir $=1$ \&article $=1013 \&$ context $=$ gerontologyinstitute_pubs.

Coleman JS (1990) Foundations of Social Theory. Cambridge, MA: Belknap Press.

Croezen S, Avendano M, Burdorf A and Van Lenthe FJ (2015) Social participation and depression in old age: a fixed-effects analysis in 10 European countries. American Journal of Epidemiology 182, 168-176.

Dávila MC (2018) The relationship between social networks and volunteerism among seniors. Journal of Social Service Research 44, 38-49.

Dewey ME and Prince MJ (2005) Mental health. In Börsch-Supan A and Jürges H (eds), Health, Ageing and Retirement in Europe - First Results from the Survey of Health, Ageing and Retirement in Europe. Mannheim, Germany: MEA Eigenverlag, pp. 108-117.

Estes CL and Mahakian JL (2001) The political economy of productive aging. In Morrow-Howell N, Hinterlong JE and Sherraden M (eds), Productive Aging: Concepts and Challenges. Baltimore, MD: Johns Hopkins University Press, 197-213.

Firth D (1993) Bias reduction of maximum likelihood estimates. Biometrika 80, 27-38.

Forbes KF and Zampelli EM (2014) Volunteerism: the influences of social, religious, and human capital. Nonprofit and Voluntary Sector Quarterly 43, 227-253.

Foster L and Walker A (2013) Gender and active ageing in Europe. European Journal of Ageing 10, 3-10.

Garavaglia E, Marcaletti F and Iñiguez-Berrozpe T (2020) Action research in age management: the Quality of Ageing at Work model. Work, Aging and Retirement. DOI:10.1093/workar/waaa025.

Gayen K, McQuaid R and Raeside R (2010) Social networks, age cohorts and employment. International Journal of Sociology and Social Policy 30, 219-238.

Gonzales E and Nowell WB (2017) Social capital and unretirement: exploring the bonding, bridging, and linking aspects of social relationships. Research on Aging 39, 1100-1117.

Kim S (2020) Human, social and cultural predictors of productive activities in later life. Ageing \& Society 40, 328-347.

Lee YS, Morrow-Howell N, Jonson-Reid M and McCrary S (2012) The effect of the Experience Corps ${ }^{\oplus}$ program on student reading outcomes. Education and Urban Society 44, 97-118.

Lindley R, Baldauf B, Galloway S and Li Y (2014) Older volunteers in England: towards greater flexibility and inclusiveness? In Principi A, Jensen P-H and Lamura G (eds), Active Ageing: Voluntary Work by Older People in Europe. Bristol, UK: Policy Press, pp. 119-147.

Maestas N (2010) Back to work: expectations and realizations of work after retirement. Journal of Human Resources 45, 718-748.

McNamara T-K and Gonzales E (2011) Volunteer transitions among older adults: the role of human, social, and cultural capital in later life. Journals of Gerontology: Psychological Sciences and Social Sciences 66B, 490-501. 
Moody H (1993) What is critical gerontology and why is it important? In Cole TR, Achenbaum WA, Jakobi PL and Kastenbaum R (eds), Voices and Vision of Aging: Towards a Critical Gerontology. New York, NY: Springer, pp. xv-xli.

Morrow-Howell N, McCrary S, Hong S and Blinne W (2008) Experience Corps: the volunteer experience. Washington University, Center for Social Development, St. Louis, MO, CSD Research Brief 08-31. Available at https://csd.wustl.edu/08-31/.

Morrow-Howell N, Putnam M, Soo LY, Greenfield JC, Inoue M and Chen H (2014) An investigation of activity profiles of older adults. Journals of Gerontology: Psychological Sciences and Social Sciences 69B, 809-821.

Musick MA and Wilson J (2007) Volunteers. A Social Profile. Bloomington, IN: Indiana University Press.

Ney S (2005) Active aging policy in Europe: between path dependency and path departure. Ageing International 30, 325-342.

Oude Mulders J, Henkens K and van Dalen HP (2020) How do employers respond to an aging workforce? Evidence from surveys among employers, 2009-2017. In Czaja SJ, Sharit J and James JB (eds), Current and Emerging Trends in Aging and Work. Cham, Switzerland: Springer, pp. 281-296.

Putnam RD (2000) Bowling Alone: The Collapse and Revival of American Community. New York, NY: Simon and Schuster.

Raymond É, Grenier A and Hanley J (2014) Community participation of older adults with disabilities. Journal of Community \& Applied Social Psychology 24, 50-62.

Reinhardt JP, Boerner K and Horowitz A (2006) Good to have but not to use: differential impact of perceived and received support on well-being. Journal of Social and Personal Relationships 23, 117-129.

Sabatini F (2009) Social capital as social networks: a new framework for measurement and an empirical analysis of its determinants and consequences. Journal of Socio-economics 38, 429-442.

Serrat R, Villar F, Giuliani M-F and Zacarés JJ (2017) Older people's participation in political organizations: the role of generativity and its impact on well-being. Educational Gerontology 43, 128-138.

Strauss S (2021) Multiple engagement: the relationship between informal care-giving and formal volunteering among Europe's 50+ population. Ageing \& Society 41, 1562-1586.

Tang F (2016) Retirement patterns and their relationship to volunteering. Nonprofit and Voluntary Sector Quarterly 45, 910-930.

Tang F and Morrow-Howell N (2008) Involvement in voluntary organizations: how older adults access volunteer roles? Journal of Gerontological Social Work 51, 210-227.

van der Gaag MPJ (2005) Measurement of Individual Social Capital. Amsterdam: F\&N Boekservices.

van der Horst M, Vickerstaff S, Lain D, Clark C and Geiger BB (2017) Pathways of paid work, care provision, and volunteering in later careers: activity substitution or extension? Work, Aging and Retirement 3, 343-365.

Walker A (2006) Active ageing in employment: its meaning and potential. Asia Pacific Review 13, 78-93.

Wilson J (2000) Volunteering. Annual Review of Sociology 26, 215-240.

World Health Organization (2002) Active Ageing: A Policy Framework. Madrid: World Health Organization. Available at https://www.who.int/ageing/publications/active_ageing/en/.

Cite this article: Boerio P, Garavaglia E, Gaia A (2023). Active ageing in Europe: are changes in social capital associated with engagement, initiation and maintenance of activity in later life? Ageing \& Society 43, 1122-1140. https://doi.org/10.1017/S0144686X21001021 